Brito, C.M.O.; Aquino, T.C.H. Turismo e sustentabilidade: uma análise acerca do turismo sustentável realizado na APA de Algodoal-Maiandeua (PA) Revista Brasileira de Ecoturismo, São Paulo, v.6, n.1, jan/abr-2013, pp.285-296.

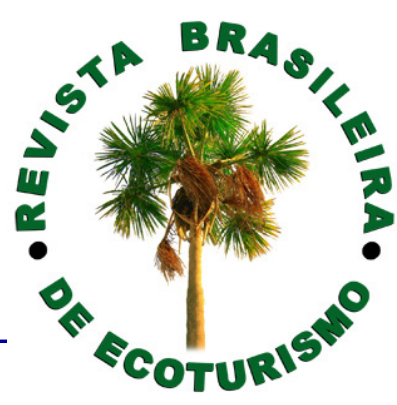

\title{
Turismo e sustentabilidade: uma análise acerca do turismo sustentável realizado na APA de Algodoal-Maiandeua (PA)
}

\author{
Tourism and sustainability: an analysis about the sustainable tourism \\ held in Environmental Protect Area Algodoal-Maiandeua (PA, Brazil)
}

\section{Celisse Maria de Oliveira Brito, Thiara Cristina Huerb de Aquino}

\section{RESUMO}

O potencial turístico do Brasil chama a atenção do cenário mundial através de suas belezas naturais, riquezas histórico-culturais e sua hospitalidade, fazendo com que várias cidades brasileiras passem a ter o turismo como uma das principais fontes de renda. Porém, junto com essa atividade encontra-se o paradigma da sustentabilidade, visto que as políticas existentes nessas cidades não integram de maneira eficaz o potencial apresentado por esses, e quando o são contemplados, não são trabalhados de forma adequada, com um planejamento coeso e sustentável. Este trabalho objetivou analisar de que forma ocorre a atividade turística na APA de Algodoal/Maiandeua (PA). Metodologicamente o caminho percorrido se fez através de pesquisa bibliográfica e documental a respeito da temática discutida; entrevistas específicas com comunitários; turistas e empresários; visitas in loco; e observação participante. Destarte, as evidências encontradas confirmam a potencialidade turística local, além de possuir uma infraestrutura básica na recepção dos visitantes, entretanto, o turismo na ilha ainda ocorre de forma desordenada. Por isso conclui-se que "certas" ações precisam ser efetivadas.

PALAVRAS-CHAVES: Sustentabilidade; Área de proteção Ambiental; AlgodoalMaiandeua; Turismo.

\section{ABSTRACT}

The tourism potential of Brazil draws the attention of the world stage through its natural beauty, historical and cultural wealth and hospitality, making several Brazilian cities become of tourism as a major source of income. However, existing public policies in these cities do not integrate effectively the potential presented by these, and when they are covered with some type of policy, are not worked adequately, with a cohesive and sustainable planning. This study aimed to examine how tourism activity occurs in Environmental Protect Area Algodoal/ Maiandeua (PA, Brazil) and whether it has contributed to environmental conservation. Methodologically the path was made through bibliographical research and documentary about the topic discussed and the locality; interviews with specific community, tourists and businessmen, on-site visits, and participant observation. Thus, the evidence found confirms the potential tourist spot, besides having a basic infrastructure in the reception of visitors, however, tourism on the island still occurs in a disorderly fashion. Therefore it is concluded that "certain" actions need to be effective.

KEYWORDS: Sustainability; Environmental Protection Area, Algodoal-Maiandeua, 
Turismo e sustentabilidade: uma análise acerca do turismo sustentável realizado na APA de AlgodoalMaiandeua (PA)

\title{
Introdução
}

A evolução do turismo nas últimas décadas nos permite identificar uma atividade em expansão, que vem ganhando importância na economia mundial. O desenvolvimento turístico, no entanto, quando praticado sem planejamento e controle, pode levar à utilização predatória dos recursos naturais, colocando em risco a sustentabilidade do destino.

O Turismo Sustentável pode ser compreendido como um segmento do Turismo que tem apresentado altos índices de crescimento, sendo uma tendência atual. Isso implica em uma demanda crescente de turistas para áreas naturais, em busca de um maior contato com a natureza.

Dessa forma, desenvolver os aspectos sustentáveis no turismo transcende a pressão por um desenvolvimento mais justo e menos predatório em seus destinos turísticos, visto que tal parâmetro tornou-se hoje condição, quase que unânime, no planejamento da atividade turística. A formulação de um projeto turístico inserido em um contexto de insustentabilidade é visto hoje, pelos estudiosos da área, como um modelo contraditório como menciona Cruz (2003, p. 30):

\begin{abstract}
Apesar de diversos autores ressaltarem os efeitos negativos do turismo sobre ambientes naturais, é preciso reconhecer que a degradação dos ambientes, de modo geral não interessa ao turismo porque este tem o espaço como principal objeto de consumo. A degradação de ambientes naturais ou urbanos provocada pelo turismo contraria a lógica de reprodução da atividade. Nesse caso, ou há algum erro estratégico de planejamento subjacente ao processo de apropriação dos lugares pela atividade ou, simplesmente, o planejamento jamais existiu.
\end{abstract}

Uma das bases fundamentais, que compõe o Turismo Sustentável e que constantemente enquadra-se erroneamente fora dos objetivos de planejamento, diz respeito à participação comunitária na ampliação do controle do desenvolvimento da atividade turística, através da garantia de sua participação ativa no planejamento e desenvolvimento do turismo.

O objetivo desse estudo é apresentar a discussão sobre Turismo na Área de Proteção Ambiental - APA de Agodoal-Maiandeua, analisando a prática da atividade turística na região, pois para que o turismo gere beneficio socioambiental é necessário que haja um planejamento adequado de acordo com a peculiaridades de cada localidade, enfatizando suas potencialidades juntamente com a inclusão social.

Metodologicamente a pesquisa se baseou primeiramente em bibliografias e documentos sobre a temática discutia. Em um segundo momento iniciou-se uma etapa de levantamento de dados através de visitas in loco, observação participante (incluindo todo o procedimento de transporte, hospedagem comunitária, entretenimento, alimentação e vivencia local), reprodução fotográfica e audiovisual. Culminando em consultas a documentos eletrônicos, iconográficos e relatórios técnicos. 


\title{
Turismo e desenvolvimento sustentável
}

O primeiro conceito oficial de desenvolvimento sustentável foi criado em 1987. Na ocasião foi divulgado o relatório "Nosso Futuro Comum" ou "Relatório de Brundtland", elaborado pela Comissão Mundial Sobre Meio Ambiente e Desenvolvimento - CMMAD, a pedido da Organização das Nações Unidas - ONU. Tal documento foi resultado de mais de três anos de trabalho, o qual debatia sobre a conservação da natureza e o desenvolvimento no mundo. Este documento definia o desenvolvimento sustentável como: "aquele que atende às necessidades do presente sem comprometer a possibilidade de as gerações futuras atenderem as suas próprias necessidades" (CMMAD, 1987, p. 6).

O relatório Nosso Futuro Comum é considerado um marco nas discussões sobre meio ambiente e chamou a atenção para o fato de que o desenvolvimento e o crescimento econômico resultam no comprometimento dos ecossistemas e que por isso, o meio ambiente não pode ser visto separadamente. Seria necessária uma forma mais consciente para que tal desenvolvimento acontecesse, sem o comprometimento dos recursos esgotáveis do planeta, e com isso, evitar o surgimento de grandes prejuízos na qualidade de vida das gerações futuras, questão que alavancou as ideias de desenvolvimento sustentável.

Com a realização de vários eventos posteriores em que o tema do desenvolvimento sustentável tornava-se o principal assunto dos debates, o conceito obteve ampla divulgação e se difundiu entre vários atores da sociedade, sendo possível posteriormente, a observação da evolução do conceito, cuja inclusão dos fatores econômicos e sociais se instauram como mostra Magalhães, Andrade e Dias (2005, p. 19):

\begin{abstract}
O desenvolvimento sustentável pode ser definido como uma modalidade de desenvolvimento que se preocupa com a satisfação das necessidades atuais das populações, sem, entretanto, comprometer as necessidades das gerações futuras. Isso significa que ele deve ser ecologicamente equilibrado, socialmente justo e economicamente viável.
\end{abstract}

Deve-se salientar que o desenvolvimento sustentável não significa ações de paralisação das atividades econômicas, mas sim, uma melhor forma de planejamento que vise o aproveitamento dos recursos naturais sem excesso.

Nesse parâmetro encontra-se a atividade turística que nas últimas décadas vem se consolidando mundialmente, sendo uma alternativa capaz de aliar o desenvolvimento econômico com a sustentabilidade. E na atual abordagem de desenvolvimento, "o turismo é um elo do local com o global" (CORIOLANO, 2003). E no Informe de Brundtland", (OMT, 1993, p. 15) define o desenvolvimento turístico sustentável como aquele que: 
Turismo e sustentabilidade: uma análise acerca do turismo sustentável realizado na APA de AlgodoalMaiandeua (PA)

[...] atende às necessidades dos turistas atuais e das regiões receptoras e ao mesmo tempo protege e fomenta as oportunidades para o turismo futuro. Concebe-se como um caminho para a gestão de todos os recursos de forma que possam satisfazer-se as necessidades econômicas, sociais e estéticas, respeitando ao mesmo tempo a integridade cultural, os processos ecológicos essenciais, a diversidade biológica e os sistemas que sustentam a vida (apud DIAS, 2003, p. 68).

Com essa declaração, a OMT passou a abranger princípios como a conservação do meio natural, histórico e cultural, necessidade de planejamento, gestão pública sustentável e a distribuição dos benefícios ocasionados pelo turismo e o meio ambiente à sociedade.

Nesse contexto o turismo sustentável se destaca como fundamental ferramenta de aliar a proteção ambiental e a inclusão social nas comunidades envolvidas, priorizando a busca por alternativas ecológicas capazes de gerar benefícios às populações receptoras sem agredir o meio ambiente.

Através do turismo sustentável houve possibilidade de visitar uma área natural para vivenciar uma cultura tradicional, de forma responsável, prática que começou a cativar inúmeras pessoas que, ao realizar uma viagem, se preocupam com a preservação do local e, também, com a sobrevivência desses habitantes. Assim, esse segmento turístico foi percebido como pilares responsáveis do pensar turístico, tais como 0 :

\begin{abstract}
Impacto ambiental mínimo; (2) Impacto mínimo em - e respeito máximo às - culturas anfitriãs; (3) Máximo beneficio econômico para as comunidades de base do país anfitrião; e, (4) Satisfação recreacional máxima para os turistas participantes (HETZER, apud FENNELL, 2002 p. 40).
\end{abstract}

O turismo sustentável apresenta vários benefícios para o ambiente natural. Para Swarbrooke (2000, p.14), ele estimula uma compreensão dos impactos do turismo no ambiente natural, cultural e humano; incorpora planejamento e zoneamento assegurando o desenvolvimento do turismo adequado à capacidade de carga do ecossistema além demonstrar a importância dos recursos naturais e culturais.

Vale esclarecer que crescimento e desenvolvimento, tidos muitas vezes como sinônimos são palavras com sentidos distintos. O crescimento não significa automaticamente igualdade social, visto que não leva em consideração aspectos de melhoria da qualidade de vida que não seja o acúmulo de riquezas, geralmente encontrados em uma parcela reduzida da sociedade. O desenvolvimento, também se avalia através da geração de riquezas, porém objetivando uma melhor distribuição da mesma, refletindo em uma melhor qualidade de vida dos indivíduos, considerando, portanto a qualidade ambiental e social do planeta como elementos essenciais para o desenvolvimento humano. 
Brito, C.M.O.; Aquino, T.C.H.

\section{Contextualização e características da área de estudo}

A área de proteção ambiental Algodoal-Maiandeua é subordinada administrativamente ao município de Maracanã/PA, localizado na Amazônia Atlântica, litoral nordeste do estado do Pará. Segundo a Fundação Instituto Brasileiro de Geografia e Estatística (IBGE), é constituída por duas ilhas denominadas Algodoal e Maiandeua, porém, as comunidades residentes consideram que seja apenas uma ilha denominada Maiandeua, sendo a principal vila chamada de Algodoal.

A ilha faz parte da microrregião geográfica do Salgado, entre as coordenadas

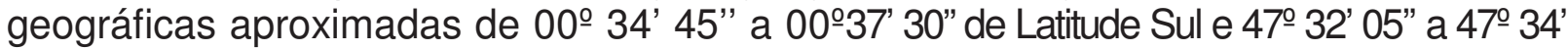
12"de Longitude (W.Gr.). Seus limites geográficos são: ao Norte, o Oceano Atlântico, ao Sul, o furo da Mocooca, a Leste, a Baía de Maracanã e a Oeste, a Baía de Marapanim (Figura 1).

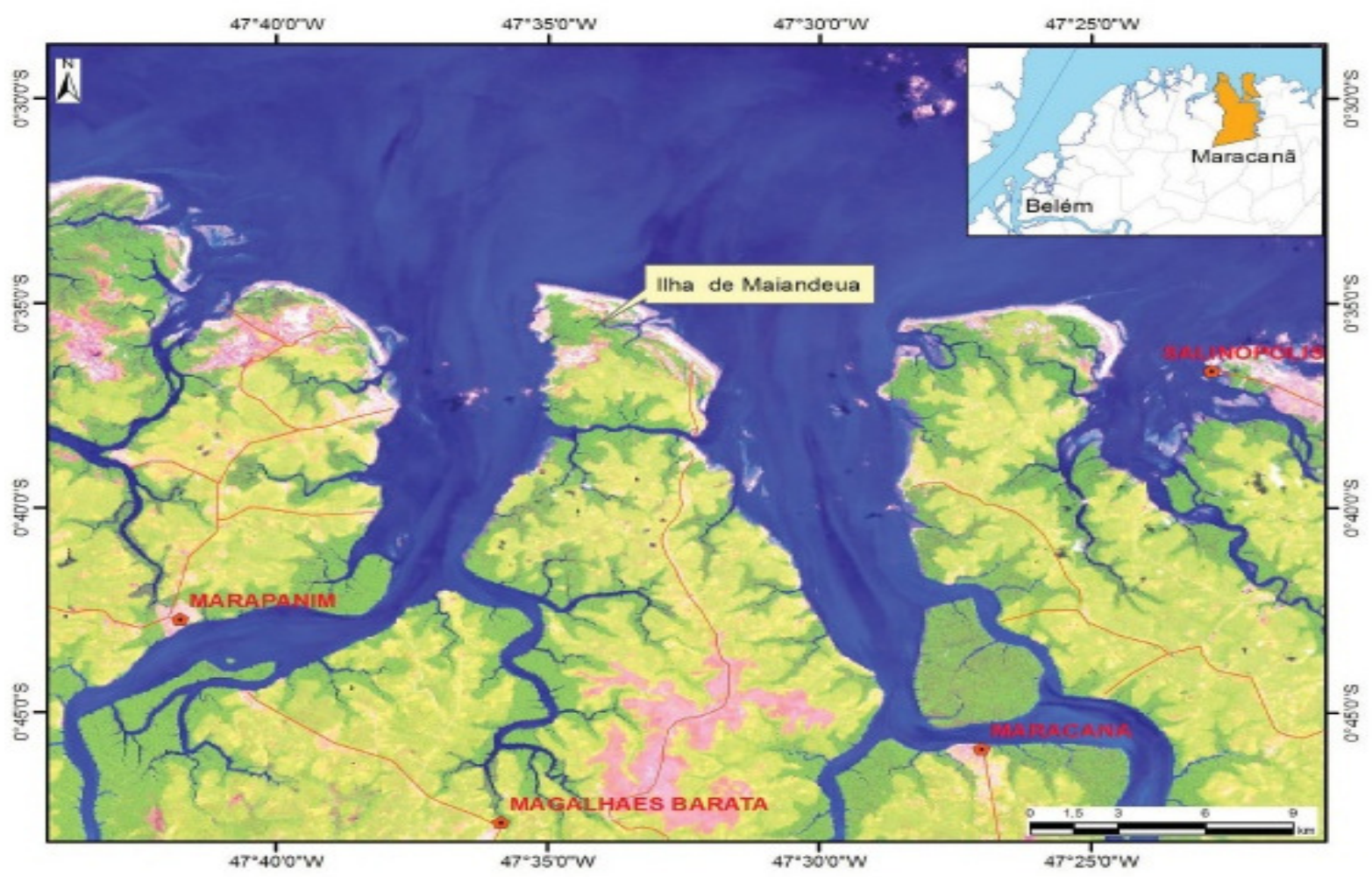

Figura 1: Mapa de satélite da llha de Algodoal. Fonte: Galeria de fotos, 2008.

Figure 1: Map of satellite of the Isle Algodoal. Source: Photo Gallery, 2008.

A ilha encontra-se dentro de uma área de Proteção Ambiental - APA criada por uma lei estadual em 1990 pela lei no 5.621 , de 27/11/1990. Que tem por objetivo conciliar as atividades humanas com a conservação da vida silvestre, a proteção dos demais recursos naturais e a melhoria da qualidade de vida da população, por meio de um trabalho conjunto entre órgãos do Governo e a participação ativa da comunidade.

As áreas de proteção ambiental estão inseridas em um sistema maior, denomi- 
Turismo e sustentabilidade: uma análise acerca do turismo sustentável realizado na APA de AlgodoalMaiandeua (PA)

nado de Unidades de Conservação - UC. Este sistema abrange, segundo a Revista Visão e Ação (2000), um elenco de categorias de manejo que protege toda a diversidade de ecossistemas do país, bem como a diversidade de ambientes cênicos e de belezas naturais, o patrimônio genético, as espécies raras ou em perigo de extinção, e outros aspectos naturais e culturais.

A palavra Maiandeua significa "Mãe da Terra" e a palavra Algodoal foi um apelido dado pelos pescadores na década de 1920, em virtude da abundância de uma planta nativa conhecida como algodão de seda, cujas sementes, possuem filetes brancos e que ao flutuarem ao vento, lembram o algodão.

Há duas maneias para se chegar à ilha. Para se chegar a Algodoal via Marudá, o percurso é de $160 \mathrm{~km}$, com saída de Belém e mais uma travessia de barco de aproximadamente 40 minutos. Já o acesso via Maracanã é mais longo, pois, com saída de Belém, a viagem é de aproximadamente 3 horas pela estrada, tempo necessário para fazer o percurso de 170 km (MENDES; SILVA; SANTOS, 2001, p.103).

Aproximadamente na década de 60 a llha de algodoal era refúgio de intelectuais paraenses que procuravam o local para descansar e contemplar a natureza. $\mathrm{Na}$ década seguinte, Algodoal ganhou fama de "Paraíso Perdido", um lugar de natureza exuberante e que proporcionava extrema liberdade, daí em diante, outras comunidades começaram a se instalar na ilha, como a comunidade Hippie e os famosos "gringos", visitantes internacionais em que alguns acabaram fixando residência. (NÓBREGA, 2008).

Com isso a partir da década de 80 até os dias atuais, a atividade turística na Ilha, vem se efetivando mais intensamente principalmente nos períodos de alta temporada Junho/Julho e Dezembro/Janeiro, meses em que a ilha fica extremamente lotada gerando um grande impacto ambiental, visto que a ilha não possui capacidade para suportar a quantidade de turistas existente na região, ocasionando poluição uma sonórica e ambiental.

Segundo expectativas de Molina (2001) e da WWF-Brasil (2001) essa acelerada expansão do turismo continuará em altas taxas e haverá significativo acréscimo no volume de viagens voltadas para o relacionamento do homem com a natureza, tendendo para o crescimento exponencial do número de pessoas que visitam parques e áreas naturais. Porém, sabe-se que a atividade turística não planejada provoca uma crescente, intensa e constante pressão sobre os espaços naturais utilizados como atrativos, bem como sobre o patrimônio histórico e cultural de uma determinada área.

Com a tentativa de conter a degradação ambiental, "desde Agosto de 2006, foi criado um Conselho Gestor da ilha, composto por onze associações da sociedade civil e onze órgãos públicos, que vem discutindo em reuniões periódicas os problemas da APA". (NÓBREGA, 2008 p. 53). E ainda para a minimização dessa problemática criou-se um Plano de Manejo, principal instrumento de preservação e inclusão social da APA.

Na ilha também existem duas Organizações Não Governamentais - ONGs: a SUATÁ e o GAF. Segundo entrevista realizada com o senhor Marcelo responsável 
pela ONG SUATÁ, as ONG's em algodoal objetivam promover ações de educação ambiental, de cidadania, incentivando atitudes ambientalmente adequadas, influenciando nas políticas públicas, e enfim, criando condições favoráveis ao desenvolvimento sustentável, garantindo a participação da comunidade, com vistas à melhoria da qualidade de vida dos moradores e visitantes daquela unidade de conservação.

Atualmente, a Suatá trabalha para defender e valorizar a identidade cultural da APA de Algodoal/Maiandeua e conservar o patrimônio natural e histórico da ilha, buscando o desenvolvimento do turismo sustentável. Desde 2005 a ONG vem criando ações com o objetivo de conscientização ambiental, como uma campanha de sensibilização ambiental no mês de Julho e capacitação de pessoas da comunidade para trabalharem como agentes ambientais. Realização de oficinas de educação ambiental, serigrafia e costura. E treinamento para estudantes com idade entre 15 a 18 anos para serem condutores de visitantes em áreas naturais da ilha.

O Gaf atua há pelo menos 11 anos na APA e já realizou várias ações na comunidade, como de oficinas ambientais através da parceria com uma faculdade de turismo do estado Pará, em que os graduandos visitaram a ilha, oferecendo oficinas para a comunidade e realizando um intercâmbio cultura e ambiental. Segundo o Senhor Marcelo a interação das ONGs com a comunidade local, os visitantes e com o órgão gestor da APA, só iniciou-se a partir da criação do Conselho Gestor da APA, pois se abriu um canal de comunicação com o poder público.

\section{O turismo na llha: atrativos culturais e naturais.}

A concentração de turistas na ilha de Algodoal/Maiandeua ocorre por moradores do próprio estado nos meses de Janeiro, Junho, Julho e Dezembro. Nos meses de Dezembro e Janeiro são as épocas mais criticas da ilha, em virtude da falta de capacidade de carga para quantidade de turistas recebidos na ilha. E nos meses de Agosto e Setembro há uma concentração maior de turistas estrangeiros. (NÓBREGA, 2008).

Normalmente, ao visitar a ilha o turista busca conhecer a rusticidade da comunidade nativa, através da rotina dos moradores além conhecer a diversidade natural, através das praias, lagos e rios. Beleza que pode ser presenciadas através da caminhada que podem ser praticadas livremente.

Outro aspecto bastante procurado é o cultural, como a dança do Carimbó que foi criada nas fazendas da região do Salgado do Estado do Pará, no século XVIII, pelos negros e escravos. A palavra carimbó, originalmente vem do nome de um dos tambores feito de um tronco oco que eram utilizados pelos negros.

Ao que se refere aos atrativos naturais à ilha possui uma riqueza inquestionável pelos seus moradores e visitantes, como a praia da Princesa com quase 14 quilômetros de extensão. Sendo a praia mais famosa e estruturada. 
Turismo e sustentabilidade: uma análise acerca do turismo sustentável realizado na APA de AlgodoalMaiandeua (PA)

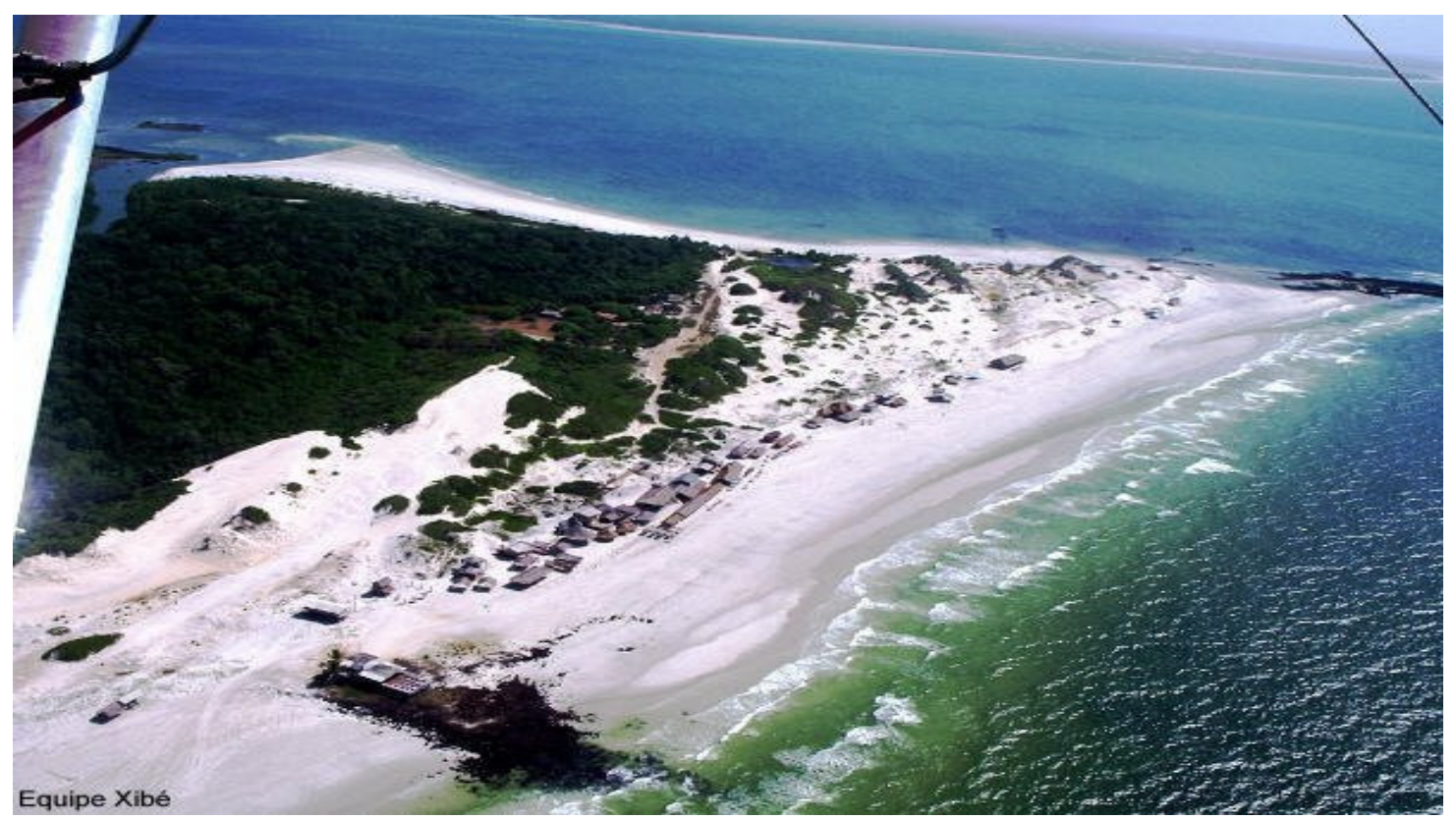

Figura 2: Ilha de Algodoal-Maiandeua. Fonte: Galeria de fotos, 2000.

Figure 2: Island Algodoal-Maiandeua. Source: Photo Gallery, 2000.

O lago da Princesa uma das principais atrações da ilha também é uma área com mangues, restingas e dunas; suas águas doce-escuras, cuja cor lembra cocacola, e suas areias claras e finas. Nos períodos de alta estação, oferece bares em funcionamento. Como o acesso ao local é feito

A Praia da Caixa D'água localiza-se em frente à vila de Algodoal. Porém apenas se recomendar tomar banho enquanto a maré está cheia, em virtude do risco. A Enseada do Costeiro é a praia mais perigosa da ilha, por apresentar as maiores ondas e haver registro de presença de tubarões.

Praia da Marieta, com cerca de $26 \mathrm{~km}$ de extensão é bastante visitada por surfistas. Para chegar à praia é necessário um passeio barco com duração aproximada de 2 horas e dependendo da estação visitante pode-se ver botos, cardumes de peixe, garças, guarás e a riqueza dos manguezais.

Existem outras praias na ilha, que são a Praia do Cação, Praia da Salina e Praia do Guarani. Todas são desertas e muito interessantes. As únicas edificações que existem nas mesmas são os barracões que são, esporadicamente, utilizados por pescadores.

Outros atrativos da ilha de Algodoal é a pescaria artesanal, que pode ser realizado através da pesca com linha nas proximidades da ilha, ou através da pescaria tradicional com rede em alto mar, que pode durar de 12 horas a dois dias. Tem também o surf, em que as melhores ondas acontecem no mês de março. $E$ as trilhas que podem ser de diurna ou noturna. Lobato, Bevilaqua e Silva (1999 p. 33). 


\section{Impactos causados pela atividade turística}

$\mathrm{Na}$ Ilha de Algodoal estão ocorrendo vários problemas ambientais, decorrentes da intensificação da atividade turística, pois os turistas em época de alta estação produzem uma grande quantidade de lixo, pois levam para a ilha grande quantidade de alimentos de preparo rápido assim como utensílios que acabam se espalhando pela ilha. Este problema vem se agravando devido à falta de uma coleta seletiva de lixo.

Com o advento da luz elétrica em 2005, houve um crescimento na atividade turística de algodoal, iniciando assim um processo de especulação imobiliária na ilha, os visitantes começaram a adquirir as moradias dos nativos e estes constroem suas novas casas em locais afastados e inapropriados para moradia, como em áreas de mangue, região considerado um ecossistema frágil por ser berçário de varias espécies de animais importantes na alimentação e economia da população local.

Há também os problemas de natureza social, como o desvio de produção que antes era a pesca e a agricultura, porém com a intensificação da atividade turística muitos moradores passaram a ter a atividade como fonte principal de subsistência, causando um desvio de cultura, e um alto índice de desemprego, pois o turismo é uma atividade sazonal, principalmente em áreas que não possuem grandes infraestruturas, por isso o ideal é que em certas localidades como Algodoal o turismo seja complementar a outras atividades básicas.

Destarte, o turismo na ilha ainda ocorre de forma desordenada, impulsionada pela massificação da atividade, principalmente nos meses de férias escolares, deixando de gerar de maneira uniforme benefícios sociais, econômicos e ambientais, trazendo muito mais impactos do que benefícios.

Por isso conclui-se que "certas" ações precisam ser efetivadas, tanto pela comunidade, governo local e federal, terceiro setor e acadêmicos científicos, para o incentivo e aperfeiçoamento do turismo local e minimização de problemas ambientais como desmatamento, lixo, queimadas, etc., possam ser resolvidos. Cabendo assim a cada instituição exercer sua função competente, estabelecendo um desenvolvimento integrado e harmônico entre os agentes do processo para a garantia do uso dos recursos naturais de forma sustentável.

\section{Considerações finais}

Não há dúvidas de que as áreas naturais do mundo devem ser preservadas para que existam, no futuro, espaços não modificados pelo homem. Estes espaços naturais podem ser utilizados para a prática da atividade turística, se possuir um planejamento consciente. Este planejamento se faz necessário para evitar os danos ambientais sobre os meios visitados e manter a atratividade dos recursos para o futuro.

O fomento do turismo sustentável juntamente com o planejamento ordenado dos espaços, dos equipamentos e das atividades turísticas, pode gerar renda para a área contribuindo assim para a preservação de seus recursos naturais relevantes e garantindo a conservação e proteção dos mesmos através do controle dos turistas. (AGNES, 2003).

No caso da ilha de Algodoal que é conhecida por suas naturais e culturais, junta- 
Turismo e sustentabilidade: uma análise acerca do turismo sustentável realizado na APA de AlgodoalMaiandeua (PA)

mente com suas características aliadas à rusticidade e simplicidade, fazem com que o local seja um destino turístico bastante procurado por pessoas que buscam praticar atividades de lazer em ambientes naturais.

Por isso o planejamento deve ser bem estruturado, com a inclusão da comunidade local para um processo socialmente e ambientalmente eficaz, atendendo os objetivos das APAs, finalizando com um rigoroso controle e supervisão constante feito por profissionais.

Porém o que se pode observar é que atividade turística em Algodoal vem crescendo de forma desordenada, sem planejamento e qualificação da comunidade, fatores que são determinantes para que o turismo seja uma atividade de caráter sustentável, causando assim menos impactos ambientais.

Devido à falta de coleta adequada e com o grande fluxo de lixo em virtude da intensificação do turismo, a problemática do lixo em Algodoal é o principal fator de grande impacto negativo no ambiente. Grande parte da população e dos estabelecimentos comerciais da ilha utilizam seus quintais como depósito de lixo orgânico e inorgânico, fazendo com que os mesmos penetrem no lençol freático, causando degradação e poluição ambiental.

Nesse contexto mostra-se a importância do turismo sustentável, como atividade que se propõe a reduzir os impactos negativos, forma de proporcionar a percepção ambiental e, consequentemente, a interpretação dos espaços vivenciados pelos visitantes que buscam os espaços naturais como destino das viagens de lazer. A percepção humana é considerada um pré-requisito básico para o alcance de diferentes níveis de conscientização ambiental

Nesse sentindo com os conhecimentos adquiridos por meio das pesquisas realizadas e apoiadas em bases científicas referenciadas neste trabalho, foi assegurado um suporte que permitiu a construção dessa proposta, pois, de acordo com Lindberg e Hawkins (1999 p. 20), "um projeto e planejamento que deve ser aplicados, a fim de minimizar o impacto sobre o meio ambiente, fornecer certo grau de auto suficiência funcional e contribuir para a melhoria da qualidade da experiência do visitante".

Sendo assim, recomendam-se para a área estudada algumas instalações que propiciem melhor qualidade da visitação e experiência estimulante dos turistas na natureza, tais como: sistema de trilhas monitoradas; placas informativas e painéis educativos (estabelecendo claramente as regras de comportamento e orientando o visitante na apreciação da natureza); mirantes; espaços para atividades educativas; placas e materiais de interpretação ambiental para identificação da flora e outros aspectos curiosos (árvores, plantas, tocas de animais, etc.).

Pelo exposto, a principal mensagem desse trabalho permite entender a importância da conservação da natureza com todos os seus componentes, cujo objetivo é a busca da harmonia do homem com a natureza. Acredita-se que as propostas apresentadas são fundamentais para se desenvolver uma gestão ambientalmente adequada.

Essas considerações desenham um cenário adequado da realidade socioambiental e situam a importância da gestão ambiental, cujo pressuposto é a existência de uma política ambiental no contexto do exercício da cidadania de todos os membros da sociedade. Portanto, ressalta-se que a gestão ambiental é o ato de administrar, de dirigir ou reger os ecossiste- 
mas naturais e sociais em que se insere o homem, em um processo de interação que atenda ao desenvolvimento das atividades humanas, à preservação dos recursos naturais e das características essenciais do entorno, dentro de padrões de qualidade definidos, tendo como última finalidade estabelecer, recuperar ou manter o equilíbrio entre a natureza e o homem.

Destarte, o turismo na ilha ainda ocorre de forma desordenada, impulsionada pela massificação da atividade, principalmente nos meses de férias escolares, deixando de gerar de maneira uniforme benefícios sociais, econômicos e ambientais. Por isso concluise que "certas" ações precisam ser efetivadas, tanto pela comunidade, governo local e federal, terceiro setor e acadêmicos científicos, para o incentivo e aperfeiçoamento do turismo local e minimização de problemas ambientais como desmatamento, lixo, queimadas, etc., possam ser resolvidos.

Cabendo assim a cada instituição exercer sua função competente, estabelecendo um desenvolvimento integrado e harmônico entre os agentes do processo para a garantia do uso dos recursos naturais de forma sustentável.

\section{Referências bibliográficas}

AGNES D. A importância do planejamento para a prática da atividade turística em Áreas de Proteção Ambiental. Revista Turismo, 2003

ALCÂNTARA, E. Prainha do Canto Verde: Turismo Socialmente Responsável e Gestão Participativa. Fortaleza, 2003. 143p. Dissertação Curso de Mestrado Profissional em Gestão de Negócios Turísticos da Universidade Estadual do Ceará.

COMISSÃO MUNDIAL SOBRE MEIO AMBIENTE E DESENVOLVIMENTO. Nosso futuro comum. Rio de Janeiro: Fund. Getúlio Vargas, 1988.

CRUZ, R. Introdução à geografia do turismo. $2^{\text {a }}$ ed. São Paulo: Roca, 2003.

COMISSÃO MUNDIAL SOBRE MEIO AMBIENTE E DESENVOLVIMENTO. Nosso futuro comum. $2^{\mathrm{a}}$ ed. Rio de Janeiro: Fundação Getúlio Vargas, 1991.

CORIOLANO, L.N.M.; LIMA, L.C. (Orgs.). Turismo comunitário e responsabilidade socio-ambiental. Fortaleza: FUNECE, 2003.

DIAS, R. Planejamento do turismo: política e desenvolvimento do turismo no Brasil. Atualizado com o Plano Nacional de Turismo (03/07) de 29-4-03. São Paulo: Atlas, 2003.

DIAS, R. Turismo sustentável e meio ambiente. São Paulo: Atlas, 2007.

FENNELL, D.A. Ecoturismo: Uma introdução. São Paulo: Contexto, 2002

FERREIRA, L.S. Políticas Educacionais e Desenvolvimento: a experiência da RESEX Marinha de Soure/Pa. Dissertação de mestrado. Belém: UFPA, 2002.

LINDBERG, K. HAWKINS, D.E. Ecoturismo: um guia para planejamento e gestão. 2. Ed. São Paulo: SENAC, 1999.

LOBATO, C.; BEVILAQUA, M.; SILVA, M.N. Plano de Desenvolvimento Ecoturístico da Área de Proteção Ambiental de Algodoal/Maiandeua. Belém, SECTAM 1999. 
Turismo e sustentabilidade: uma análise acerca do turismo sustentável realizado na APA de AlgodoalMaiandeua (PA)

MAGALHÃES, D.F.; ANDRADE, E.B.; DIAS, M.C. Uma reflexão das possibilidades turísticas e ecoturísticas do município de Ferreira Gomes. Macapá: NAEA, 1999.

MENDES, A.C.; SILVA, M.S.; SANTOS, V.F. Analise do meio físico para gestão ambiental das ilhas de Algodoal e Atalaia (NE do Pará). In: PROST, M.T.; MENDES, A.C. (orgs.). Ecossistemas Costeiros: Impactos e Gestão Ambiental. Belém: Museu Paraense Emílio Goeldi, 2001.

MONTEIRO, M. NÓBREGA, W. Gestão ambiental em unidades de conservação: reflexões e proposta acerca das instalações $(\mathrm{eco})$ turísticas na Área de Proteção Ambiental Algodoal-Maiandeua, Maracanã-Pará. VI. 8. Caderno de turismo, 69p. 2008.

REVISTA VISÃO E AÇÃO. Universidade do Vale do Itajaí. Ano 2. $n^{\circ} 4$. Itajaí: Editora da Univali, 2000. $80 \mathrm{p}$

SEABRA, G.F. Ecos do turismo: o turismo ecológico em áreas protegidas. Campinas: Papirus, 2001 (Coleção Turismo). In: DIAS, R. Turismo sustentável e meio ambiente. São Paulo: Atlas, 2007.

SWARBROOKE, J. Turismo Sustentável: conceitos e impacto ambiental. São Paulo: Aleph, 2000. $140 \mathrm{p}$

\section{Nota:}

O Informe de Brundtland, datado de 1987, relatou as premissas do que seria o Desenvolvimento Sustentável. (DIAS, 2003, p. 75).

Celisse Maria de Oliveira Brito: Instituto de Estudos Superiores da Amazônia, Belém, PA, Brasil

Email: celissinha@hotmail.com

Link para o currículo Lattes: http://lattes.cnpq.br/3438698593332327

Thiara Cristina Huerb de Aquino: Universidade Federal do Pará, Belém, PA, Brasil Email: thuerb@gmail.com

Link para o currículo Lattes: http://lattes.cnpq.br/7237934767739815

Data de submissão: 30 de junho de 2012

Data de recebimento de correções: 14 de dezembro de 2012

Data do aceite: 14 de dezembro de 2012

Avaliado anonimamente 